\title{
Genetic Analysis of a pH-Regulated Operon from Rhizobium tropici CIAT899 Involved in Acid Tolerance and Nodulation Competitiveness
}

\author{
Pablo Vinuesa, ${ }^{1,3}$ Frauke Neumann-Silkow, ${ }^{1}$ Cristina Pacios-Bras, ${ }^{2}$ Herman P. Spaink, ${ }^{2}$ Esperanza \\ Martínez-Romero, ${ }^{3}$ and Dietrich Werner ${ }^{1}$ \\ ${ }^{1}$ FB Biologie der Philipps-Universität, FG für Zellbiologie und Angewandte Botanik, Karl von Frisch Str., D-35032 Marburg, \\ Germany; ' ${ }^{2}$ Leiden University, Institute for Molecular Plant Sciences, Wassenaarseweg 64, 2333 AL Leiden, The \\ Netherlands; ${ }^{3}$ Centro de Investigación sobre Fijación de Nitrógeno-UNAM, Programa de Ecología Molecular y Microbiana, \\ Aptdo. 565A, Cuernavaca, Morelos, Mexico.
}

Submitted 29 July 2002. Accepted 30 October 2002.

\begin{abstract}
Rhizobium tropici CIAT899 is highly acid tolerant and a good competitor for Phaseolus vulgaris nodule occupancy at low $\mathrm{pH}$ values. Using Tn5 mutagenesis, we identified an operon required for acid tolerance and nodulation competitiveness. The insertion was mapped to the $5^{\prime}$ end of atv $A$, encoding a product with high sequence identity to the agrobacterial AcvB virulence protein. Complementation analyses indicated that $a t v A$ is an ortholog of $a c v B$, both genes being required for acid tolerance. A Ser/Ala substitution in the LIPASE_SER motif of AtvA resulted in an acid sensitive $\mathrm{Fix}^{+}$but very poorly competing strain, demonstrating that Ser-313 is essential for AtvA function. atv $A$ is the second gene in an operon that is transcriptionally upregulated by acid shock. The acid-responsive promoter was mapped to a 469-bp intergenic region located upstream of lpiA, the first gene in the operon. IpiA-like genes are found in several $\alpha, \beta$, and $\gamma$ Proteobacteria that interact with eukaryotic host cells, and they are predicted to encode membrane proteins related to the $\mathbf{F m t C} / \mathrm{MprF}$ family from low $\mathbf{G}+\mathrm{C}$ Firmicutes. The latter proteins are involved in resistance to cationic antimicrobial peptides. A nonpolar deletion in lpiA caused a sevenfold decrease in relative nodulation competitiveness.
\end{abstract}

Additional keywords: gusA, lipolytic enzymes, symbiosis.

Research on the genetic and physiological basis of acid tolerance in rhizobia is both of practical and fundamental significance for several reasons. Acid soils constrain nodulation and $\mathrm{N}_{2}$ fixation in many legume-Rhizobium symbioses of agronomic interest (Glenn et al. 1999). Since both the micro- and the macrosymbiont can represent the acid-sensitive component of the symbiosis, investigations aimed at finding acid-tolerant plant germplasm and compatible rhizobial strains are of notable agronomic and ecological relevance (Graham et al. 1982; Howieson and Ewing 1986; Priefer et al. 2001; Zahran 1999). Furthermore, the roots of $\mathrm{N}_{2}$-fixing legumes are known to secrete $\mathrm{H}^{+}$and organic acids that sharply decrease the $\mathrm{pH}$ of the

Corresponding author: Pablo Vinuesa; Telephone: + 52777 3131697; Fax: + 52777 3175581; E-mail: vinuesa@ cifn.unam.mx.

Nucleotide sequence data reported are available in the GenBank database under the accession number AF433669. rhizosphere up to 2 units below that of the surrounding bulk soil (Marschner 1995). Hence, acidity is very likely a stress factor for bacteria inhabiting $\mathrm{N}_{2}$-fixing legume rizospheres. Finally, rhizobia, as intracellular microsymbionts, have been postulated to inhabit an acidic lytic compartment, the symbiosome which, in several aspects, resembles the phagosomes inhabited by mammalian intracellular pathogens (Mellor 1989; Parniske 2000; Roth et al. 1988; Udvardi and Day 1997). Genetic evidence has been recently presented suggesting that rhizobia and other rhizobacteria face several environmental stresses in the rhizosphere in addition to acidity, including osmotic and oxidative stresses, which rhizobial bacteroids also sense in the symbiosome compartment (LeVier et al. 2000; Nogales et al. 2002; Oke and Long 1999a; Rainey 1999). Therefore, the capacity of the microsymbiont to adapt to acidity and other stress factors can be postulated to be of critical importance for its optimal symbiotic performance.

Our aim was to identify novel rhizobial genes required for acid tolerance and to explore their role in symbiosis. For this purpose, $R$. tropici CIAT899 was chosen as the model organism, since this strain is well known to be highly tolerant to several environmental stressors including acidity, being able to grow on media acidified down to pH 4.0 (Graham et al. 1994; Martínez-Romero et al. 1991). Furthermore, strain CIAT899 is a good competitor for bean nodule occupancy in acid environments, both under laboratory and field conditions (Streit et al. 1992; Vlassak et al. 1996).

Presently, very little is known about the genetic or physiological basis of the strong acid-tolerance exhibited by $R$. tropici CIAT899 (Graham et al. 1994). Several reports describe the $\mathrm{pH}$-dependent differential expression of proteins in this strain by one- or two-dimensional sodium dodecyl sulfate (SDS)polyacrylamide gel electrophoresis analysis, some of which have been identified by N-terminal sequencing (Aarons and Graham 1991; Peick et al. 1999; Steele et al. 2000). However, a genetic analysis of the loci encoding for these $\mathrm{pH}$-regulated proteins has not been reported. Tn5 insertion mutagenesis coupled with selection on acidified media was used to identify $R$. tropici CIAT899 derivatives unable to grow on them. Recently, a first report was published describing an acid-sensitive mutant of CIAT899 (Riccillo et al. 2000) that carries a Tn5-luxAB insertion in the $g s h B$ gene, rendering this strain unable to synthesize glutathione.

Relatively little is known about the genetic or physiological basis of acid tolerance in other rhizobia (Graham et al. 1994; 
Glenn et al. 1999), a subject that has been intensively studied in enteric and lactic acid bacteria (Foster 1999). Most of the work on this topic in rhizobia, including the identification of genes involved in acid tolerance, has been performed with moderately acid tolerant, Mediterranean isolates of Sinorhizobium meliloti, particularly strain WSM419. This strain is significantly more acid tolerant than common $S$. meliloti laboratory strains such as 1021 and has therefore been used with notable success as an inoculant for pasture medics at sites with moderate soil acidity in western Australia (Glenn et al. 1999). A physiological trait shared by acid-tolerant rhizobia is their ability to maintain a slightly alkaline intracellular $\mathrm{pH}(\mathrm{pHi})$ when grown on media buffered at moderate acidity, while in acid-sensitive strains the $\mathrm{pHi}$ decreases with the $\mathrm{pH}$ of the medium (Chen et al. 1993; O'Hara et al. 1989; Riccillo et al. 2000). Different rhizobial species are also known to exhibit an acid tolerance response (ATR) (Aranda-Rickert et al. 2000; O'Hara and Glenn 1994).

Here, we report on the effects of nonpolar mutations in lpiA and atvA from $R$. tropici CIAT899 on acid-tolerance and nodulation competitiveness and discuss implications of these genes in symbiosis and pathogenesis.

\section{RESULTS}

Isolation of acid-sensitive Tn5 insertion derivatives of CIAT899 and their generation times at different pH values. A Tn5-induced mutant bank of Rhizobium tropici CIAT899 was generated, using the suicide plasmid pSUP1011 (Simon et al. 1983). Over 2,300 $\mathrm{Km}^{\mathrm{r}}$ transconjugants were obtained on the primary selection plates $(20 \mathrm{E}+\mathrm{Km} 150)$. The transposition frequency was estimated to be about $3.1 \times 10^{-4}$. From these, 1,728 were randomly chosen for replica plating on different media (discussed below) to identify acid-sensitive derivatives. These were found at a frequency of $0.3 \%$, and auxotrophs were found at a frequency of $0.23 \%$. Two classes of acid-sensitive mutants were obtained: those not growing in buffered MAM (25 mM Homopipes) or 20E broth at pH 4.5 (e.g., 899-PV4 and 899-PV9) and those still capable of some albeit significantly reduced growth (strains 899-PV1, 899-PV2, 899-PV10). In this study, we report on the highly acid-sensitive strain 899PV4. The generation times of the strains relevant to this study at different $\mathrm{pH}$ values are listed in Table 1 . Notice that, at $\mathrm{pH}$ 6.8 , strain $899-\mathrm{PV} 4$ has a generation time that is about $12 \%$ longer than that of the wild type.

\section{Strain 899-PV4 displays a delayed nodulation}

and elicits $\mathrm{Ndv}^{-}$and $\mathrm{Fix}^{-}$nodules on Phaseolus vulgaris.

The nodules induced by strain $899-\mathrm{PV} 4$ on common bean plants were irregular in size, white, and did not develop fully $\left(\mathrm{Ndv}^{-}\right)$after 18 to 21 days postinoculation (dpi), as judged by

Table 1. Generation times ( $\mathrm{g}$ ) of selected strains at different $\mathrm{pH}$ values

\begin{tabular}{lccl}
\hline Strain & $\begin{array}{c}\mathbf{g}(\mathbf{h}) \text { at } \\
\mathbf{p H ~ 6 . 8}\end{array}$ & $\begin{array}{c}\mathbf{g}(\mathbf{h}) \text { at } \\
\mathbf{p H ~ 5 . 5}\end{array}$ & $\begin{array}{c}\mathbf{g}(\mathbf{h}) \text { at } \\
\mathbf{p H ~ 4 . 9}\end{array}$ \\
\hline CIAT899 & 2.48 & 2.46 & 2.86 \\
899-PV4 & 2.89 & 4.39 & Not measurable \\
899-PV4(pPV4EH-MCS3) & 2.92 & 2.95 & 3.12 \\
899-PV4(pKW41) & 2.53 & 2.48 & 2.92 \\
899-AtvA(S/A) & 2.49 & 4.37 & Not measurable \\
899-lpiA41 & 2.55 & 2.46 & 3.04 \\
B119 & 2.30 & ND & Not measurable \\
B119(pPV4EH-M3) & 2.34 & ND & 2.97 \\
B119(pKW 1) & 2.29 & ND & 2.89 \\
\hline
\end{tabular}

${ }^{a}$ Cultures grown in $20 \mathrm{E}$ buffered with $20 \mathrm{mM}$ MES; ND $=$ not determined.

${ }^{\mathrm{b}}$ Cultures grown in 20E buffered with $25 \mathrm{mM}$ Homopipes. their smaller size and the lack of characteristic lenticels of mature and efficient bean nodules (data not shown). These nodules did not express nitrogenase activity $\left(\mathrm{Fix}^{-}\right)$, as revealed by the acetylene reduction assay (data not shown). Strain 899-PV4 displayed a significant delay in nodulation. It induced only about $10 \%$ of the nodules formed by the wild type and $899-\mathrm{G} 1$ during the first 8 to $14 \mathrm{dpi}$. After $21 \mathrm{dpi}$, this difference was less pronounced (data not shown). Light and electron microscopy of nodule sections induced by CIAT899-PV4 revealed that the mutant entered nodular tissues by infection threads but did not form stable symbiosomes in highly vacuolated host cells (data not shown).

\section{Strain 899-PV4 carries a single Tn5 insertion at the $5^{\prime}$ end of an ORF with high sequence similarity to the Agrobacterium tumefaciens \\ chromosomal virulence locus acvB.}

Southern hybridization analysis of BamHI- and EcoRI-digested genomic DNA of 899-PV4 probed with a digoxigenin (DIG)-labeled fragment of the Tn5 nptII marker identified single hybridizing EcoRI and BamHI fragments of 12 and $3.8 \mathrm{~kb}$, respectively, indicating that a single insertion is present in this strain (data not shown). The latter was cloned into the BamHI site of pBluescript SK (pSK), taking advantage of the Km resistance conferred by the nptII gene and named p899PV4BSK. The flanking genomic DNA segment of p899PV4BSK was polymerase chain reaction (PCR)-amplified, using $P f u$ polymerase and primer Tn5-77/58EB together with M13r, and was cloned as an EcoRI fragment into pSK, yielding p899PV4EPCR. Both strands of this plasmid were sequenced to map the Tn5 insertion junction point. A BLASTX search with the 734bp-long genomic DNA fragment in p899PV4E-PCR resulted in a highly significant match (E value $1 \mathrm{xe}^{-60}$ ) to the Agrobacterium tumefaciens AcvB protein (residues 68 to 306), a chromosomally encoded periplasmic protein of unknown biochemical function (Wirawan et al. 1993; Kang et al. 1994) that is strictly required for virulence in nopaline producing strains (Kalogeraki and Winans 1995; Majumder et al. 1999; Pan et al. 1995).

\section{Isolation of CIAT899 cosmids that restore} acid tolerance and symbiotic proficiency in 899-PV4.

A CIAT899 cosmid library (Vargas et al. 1990) was conjugally transferred en masse into the acid-sensitive strain 899-PV4. An aliquot of the conjugation mixture was plated on selective MAM medium (pH 4.2, buffered with $25 \mathrm{mM}$ Homopipes), and another aliquot was used to inoculate common bean seedlings. More than 20 transconjugants were isolated on MAM plates, indicating that they contained complementing cosmids that restored acid tolerance in 899-PV4. Plants inoculated with the transconjugant pool formed some fully developed and $\mathrm{N}_{2}$-fixing nodules on the upper part of their root systems. Bacteria could be recovered from these nodules on selective 20E plates (Km100 and Tc7.5). Five cosmids each were isolated from transconjugants selected on MAM plates and transconjugants isolated from nodules. Restriction analysis of these 10 cosmids revealed that they were identical. The cosmid restoring acid tolerance and symbiotic proficiency was designated pPV4cos1.

\section{Restriction mapping of pPV4cos1 and the identification of a 5.1-kb cosmid subclone that restores acid tolerance in $R$. tropici 899-PV4 and virulence in A. tumefaciens B119.}

A hybridization probe was derived from p899PV4E-PCR to probe pPV4cos 1 digested with several restriction enzymes. A hybridizing 5.1-kb HindIII-EcoRI fragment was subcloned into pSK, yielding pPV4EH-SK. The insert of this plasmid was subcloned as a KpnI-SmaI fragment into the broad host range 
vector pBBR1-MCS3 (Kovach et al. 1995), resulting in pPV4EH-MCS3. The latter was mobilized into A. tumefaciens B119 (acvB::Tn5) and 899-PV4, and the transconjugants were tested for virulence and acid tolerance, respectively. As shown in Table 1, pPV4EH-MCS3 is sufficient for restoring acid tolerance in 899-PV4. Plasmid pKW $\Delta 1$, carrying an A. tumefaciens insert that complements the avirulent strain B119 (Wirawan et al. 1993), also restores acid tolerance in strain 899-PV4 (Table 1). Furthermore, pPV4EH-MCS3 genetically complements strain B119, which regains virulence both on Nicotiana tabacum cv. Petite Havanna and on Kalanchöe pinnata (Fig. 1). From these results, we concluded that the gene disrupted in 899-PV4 and the $A$. tumefaciens $a c v B$ locus are orthologs. We named the $R$. tropici ortholog atvA, for acid tolerance and virulence. Finally, we discovered that strain B119 is also acid sensitive, whereas $\mathrm{B} 119(\mathrm{pKW} \Delta 1)$ is not (Table 1). However, none of these plasmids, besides pPV4cos1, restored symbiotic proficiency in 899-PV4, suggesting that the insertion in strain 899-PV4 exerts a polar effect.

\section{Sequence analysis}

\section{of the 5.1-kb DNA insert cloned in pPV4EH-SK.}

The genetic and physical maps of the 5,077-bp HindIIIEcoRI DNA fragment sequenced in this study are shown in Figure 2A. Three open reading frames (ORFs) with high coding probability were detected on this fragment by codon usage analysis, FrameD, and BLAST searches. Starting at the HindIII site, a 5'-end truncated ORF (405 bp) was located in frame +1 , encoding a product with strong sequence similarity to the chromosomally encoded hypothetical transmembrane proteins SMc02638_AA (NP_385191; E value 9e $\mathrm{e}^{-48} ; 62 \%$ identity and $77 \%$ similarity) and Mlr3948 (NP_104939; E value 4e ${ }^{-45} ; 59 \%$ identity and $73 \%$ similarity) of Sinorhizobium meliloti 1021 and Mesorhizobium loti MAFF303099, respectively. These proteins have no known function and are related to the hypothetical proteins Cg10705 (NP_599957) and PA0808 (NP_249451) from Corynebacterium glutamicum and Pseudomonas aeruginosa, respectively.

Downstream of ORF1 follows a 469-bp intergenic spacer (IGS) on which the neural network for promoter prediction located a potential promoter (sites 667 to 716) with a high probability score $(r=0.87)$. Mapping of the promoter to this IGS is also strongly supported by the complementation analyses (discussed above).

Position 875 starts a 2,607-bp-long ORF predicted to encode a 94.4-kDa product (ORF2607) with strong overall sequence similarity to the low $\mathrm{pH}$-inducible protein LpiA from $S$. meliloti (Glenn et al. 1999). These share with other phylogenetically related proteins several $\alpha, \beta$, and $\gamma$ Proteobacteria (Fig. 2B) from a conserved long N-terminal hydrophobic, and a hydrophilic C-terminal domain, displaying strikingly similar hydrophylicity plots (Fig. 2C). They are predicted by the PSORT and TMpred servers to be inner membrane proteins with 13 transmembrane helices. No matches to PROSITE motifs could be found for ORF2607. The proteobacterial lpiA family is phylogenetically related to the FmtC/MprF family from low G+C Firmicutes. Noteworthy, LpiA-like proteins are also encoded by methanogenic archaea in the genus Methanosarcina, which might have acquired the locus from an eubacterial donor by lateral transfer in ancient times, as indicated by the low $\mathrm{G}+\mathrm{C}$ content of lpiA-like genes from Methanosarcina spp. (similar to their genomic background), which is significantly lower than the $\mathrm{G}+\mathrm{C}$ content of proteobacterial lpiA genes (Fig. 2B). The hydrophobic N-termini of LpiA and FmtC/MprF family members contain the ProDom PD037692 domain (at positions 23 to 285). This domain corresponds to the cluster of orthologous groups (COG) of proteins COG0392
(Tatusov et al. 2001) comprising predicted integral membrane proteins. The C-termini of members of both families have a strong sequence similarity to the conserved hypothetical proteins CC2047 from Caulobacter crescentus and YfiX from Bacillus subtilis. These sequence stretches all share the PD014386 domain placed within the COG2898, which corresponds to an uncharacterized bacterial conserved region (Fig. 2B).

The stop codon of ORF2607 overlaps with the ATG start codon of a 1,383-bp-long ORF. The Tn5 insertion in 899-PV4 was mapped to the $5^{\prime}$ end of this ORF (between nucleotide sites 210 and 211). The sequence similarity of the deduced gene product to AcvB from A. tumefaciens is particularly strong at its C-terminus from positions 268 to 458 (60\% identity and $78 \%$ similarity). This region is also highly similar to the VirJ product encoded by Ti plasmids of the octopine type (Fig. 2B); the latter, however, lacking the less conserved N-terminal domain of AcvB-like proteins (Kalogeraki and Winans 1995; Pan et al. 1995). The first $27 \mathrm{~N}$-terminal residues of AtvA most likely encode a signal peptide (PSORT score = 0.92 ) that is probably cleaved off between residues A27 and E28 of the preprotein (Fig. 2A). The mature protein is predicted to have a mass of $46.3 \mathrm{kDa}$ and to have a periplasmic localization (PSORT score $=0.932$ ) after export by the general secretory pathway (Pugsley 1993).

BLAST searches at the general and microbial genome databases indicated that several $\alpha, \beta$, and $\gamma$ Proteobacteria, most of which are plant symbionts or plant and animal pathogens, also encode AcvB/VirJ-like proteins (Fig 2B). These proteins all produce highly significant matches with the PD039168 domain, and most of them are encoded by operons that contain lpiA-like genes preceding the $a c v B$ orthologs. The low syntheny found around lpiA/acvB-like operons is noteworthy even within closely related bacteria (Fig. 2B), suggesting that these genes may have been subjected to multiple lateral transfer events. With the exception of SMc00613, XF2679, and XF0754, the other proteins are predicted by the PSORT server to have a periplasmic location. This has been confirmed experimentally for the A. tumefaciens AcvB and VirJ proteins (Kang et al. 1994; Kalogeraki and Winans 1995; Pan et al. 1995). It is noteworthy that we found that all AcvB-like proteins contain the LIPASE_SER consensus motif (Prosite No. PS00120), located at positions 307-316 (VVLVGYSFGA) of the mature AtvA protein (Fig. 2A). Conserved D/E and $\mathrm{H}$ residues (AtvA codons 388 and 411) characteristic of the serine protease catalytic triad (Brady et al. 1990) are also found in these sequences, along with two conserved $\mathrm{C}$ residues (AtvA residues 381 and 393) that are probably involved in the formation of an

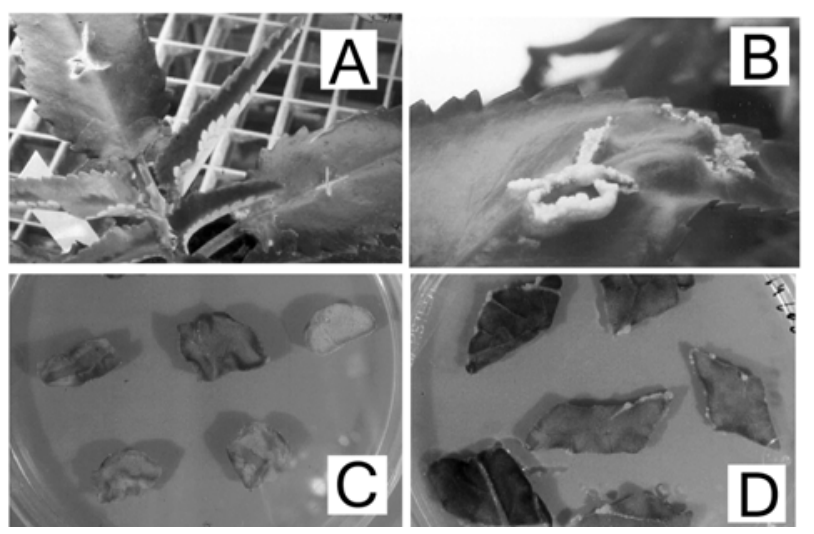

Fig. 1. Virulence assays on $\mathbf{A}$ and $\mathbf{B}$, Kalanchöe pinnata and $\mathbf{C}$ and $\mathbf{D}$, Nicotiana tabacum, using strains $\mathbf{A}$ and C, B119 and B and D, B119(pPV4EH-MCS3). Notice the formation of tumors on both hosts only by the latter (complemented) strain. 
intramolecular disulfide bond found in most lipolytic enzymes (Arpigny and Jaeger 1999).

A perfect 10-bp inverted repeat (taatgtgctcatggcgcgcggcgtgtcttgctgccgcgcgcccttct) resembling a Rho-independent transcriptional terminator was located immediately downstream of the atvA stop codon (shown in bold). A truncated ORF with low coding probability follows the atvA gene, with a potential start ATG overlapping with the TAA stop codon of atvA and a more probable start being located at position 5,004 in the same frame and transcriptional orientation (Fig. 2A). However, FrameD (at normal sensitivity) predicts the 217-bp DNA stretch between the atvA stop codon and the EcoRI site to be an intergenic spacer, and no BLAST matches could be retrieved for this segment.

\section{Construction and analysis \\ of nonpolar mutations in lpiA and $a t v A$.}

A nonpolar 1,173-bp-long deletion affecting the entire hydrophobic PD037692 domain (Fig. 2A, B, and C) of lpiA was constructed by marker exchange using plasmid p899-lpiA $\Delta 1$ (discussed below). The resulting strain, 899-lpiA $\Delta 1$, fully and effectively nodulated $P$. vulgaris and had no significant reduction in growth rate at different $\mathrm{pH}$ values (Table 1).

The Ser residue in the LIPASE_SER motif (VVLVGYSFGA) of AtvA was exchanged by Ala to prove its presumed role as a catalytic residue. To achieve this, strain CIAT899 was mutagenized with plasmid pAtvA(S/A)-18ms via marker exchange (discussed below). Parallel streaking of transconjugants on MM (pH 6.8) and MAM ( $\mathrm{pH} 4.5)$ plates indicated that they were acid sensitive. The resulting mutant strain was designated 899-AtvA(S/A), and its generation times at different $\mathrm{pH}$ values are presented in Table 1 . Strain $899-\operatorname{AtvA}(\mathrm{S} / \mathrm{A})$ induces effective nodules on bean plants, but they appear with a slight delay, as compared with those induced by the parental strain (data not shown). From these results we concluded that: i) the $S$ residue in the lipase motif of AtvA is critical for the protein's function; ii) AtvA is required for growth on acidified media, but not for effective nodulation; and iii) the insertion in 899-PV4 is exerting a polar effect, implying that one or more genes required for nodule invasion and symbiosome maturation are located downstream of atvA on the same operon, which is consistent with the results from the complementation experiments with pPV4cos1 and pPV4EH-MCS3.

\section{Use of strain 899-G1, a gusA-tagged CIAT899 reporter strain, to quantify the relative competitiveness of mutants 899-PV4, 899-lpiA $\Delta 1$, and 899-AtvA(S/A).}

To determine the relative competitivity for nodule occupancy of the three CIAT899 mutants reported herein, a gusA-tagged reporter strain was constructed (899-G1) that carries a single mTn5gusA30 (Wilson et al. 1995) insertion in an unknown locus (data not shown). Nodulation parameters (speed of nodulation, acetylene reduction, and nodulation competitiveness) of 899-G1 were equivalent to those of CIAT899, when plants were cultivated using LN-MES at $\mathrm{pH} 6.8$ or 5.5 (Table 2). Therefore, $899-\mathrm{G} 1$ was selected as a suitable reporter strain for competition experiments.

When bean seedlings were coinoculated in a 1:1 ratio with strains 899-G1 and 899-PV4, only blue nodules could be observed after GUS staining. Using a 100-fold excess of 899-PV4 over $899-\mathrm{G} 1$, at $21 \mathrm{dpi}$ only $1.5 \pm 2.9 \%$ of the nodules remained white after GUS staining. From these results we concluded that strain 899-PV4 displays a severely reduced competitiveness for nodule occupancy.

In competition experiments with $899-\mathrm{G} 1$ (1:1 and 10:1 inoculum ratios), strain 899-lpiA $\Delta 1$ displayed a 7-fold decrease in relative competitiveness with respect to the reporter strain
(Table 2). When strain 899-AtvA(S/A) was coinoculated with 899-G1 in a 1:1 ratio most plants exhibited only blue nodules after GUS-staining. In a 10:1 ratio, the former occupied $7.9 \pm$ 0.85 of the nodules (Table 2), despite its 10-fold excess in the inoculum. These results evidence that both LpiA and AtvA are required for nodulation competitiveness.

\section{The $R$. tropici atvA gene}

is transcriptionally upregulated by acid shock.

The transcriptional regulation of the atvA locus was analyzed using RNA dot blots that were probed with a DIGlabeled runoff transcript derived from p899PV4E-PCR. As shown in Figure 3, RNA extracted from $R$. tropici CIAT899 cultures that had been acid-shocked for $1 \mathrm{~h}$ ( $\mathrm{pH} 6.8$ to 4.5$)$ hybridized nearly four times stronger with the atv $A$ probe than did total RNA isolated from cultures grown at either $\mathrm{pH} 6.8$ or 5.5 , indicating that the transcriptional output of this locus is upregulated by acid shock.

\section{DISCUSSION}

In this report, we present a genetic analysis of lpiA and atvA, the first two genes linked to a symbiotically relevant operon that is transcriptionally upregulated by acid shock in $R$. tropici CIAT899. This locus was identified by Tn5 mutagenesis coupled with selection of acid-sensitive derivatives on acidified plates, a selection procedure that has been successfully used by several research groups to identify acid tolerance related genes in rhizobia (Goss et al. 1990; Priefer et al. 2001; Riccillo et al. 2000). We identified five such mutants at a frequency close to $0.3 \%$ among 1,728 insertion mutants screened. Assuming that rhizobia contain between 5,000 and 6,000 genes (Galibert et al. 2001; Wood et al. 2001) indicates that our mutagenesis was by no means saturating, and therefore, it can be predicted that at least 15 to 20 genes contribute to acid tolerance in this strain.

The acid-sensitive strains 899-PV4 and 899-AtvA(S/A) have complex pleiotropic phenotypes that have only been partially characterized at the physiological level. Besides their basic growth characteristics reported herein, we know that their acid sensitivity is not calcium repairable (in the range of $300 \mu \mathrm{M}$ to $\left.10 \mathrm{mM} \mathrm{Ca}^{2+}\right)$, they are not more sensitive than the wild type to osmotic $(300 \mathrm{mM} \mathrm{NaCl})$ or oxidative stress $\left(1.5 \mathrm{mM} \mathrm{H}_{2} \mathrm{O}_{2}\right)$, and both are able to express an acid-tolerance response (data not shown). A critical piece of data we do not have, however, is whether they are unable to maintain a slightly alkaline intracellular $\mathrm{pH}$ as that of the growth medium drops, a characteristic of "true" acid-sensitive rhizobial mutants (Glenn et al. 1999; Riccillo et al. 2000). Without this information, we cannot conclude if the mutations in atvA are affecting directly or indirectly the inability of the respective mutants to grow in acidified media.

As reported for other acid-sensitve rhizobial mutants, the nonpolar mutant 899-AtvA(S/A) effectively nodulates its host. Therefore, it seems reasonable to conclude that acid tolerance per se is not a prerequisite for nodule invasion and symbiosome differentiation. From the growth characteristics of strain 899-AtvA(S/A), it may be inferred that most likely the $\mathrm{pH}$ in the lumen of $P$. vulgaris symbiosomes will be greater than 4.9, since this strain does not grow at $\mathrm{pH}$ values below 5.0. On the other hand, this mutant exhibits significant growth at $\mathrm{pH} 5.5$ (Table 1). Hence, $P$. vulgaris symbiosomes may not become acidic enough to hinder $\mathrm{N}_{2}$ fixation by an acid-sensitive strain such as 899-AtvA(S/A) (Mellor 1989; Udvardi and Day 1997). The competition experiments performed with 899-AtvA(S/A) strongly suggest, however, that acid sensitivity reduces the symbiotic fitness of the strain, supporting the notion that there is a link between acid tolerance and symbiotic performance, as 
postulated in the introduction. Further support for this hypothesis comes from the observation that the acid sensitive mutant CIAT899-13T2 is also outcompeted by the wild-type strain in coinoculation experiments (Riccillo et al. 2000). These observations underline the importance of performing competition assays to detect symbiotic phenotypes among acid sensitive and other environmental stress mutants and suggest that acid tolerance or acid adaptation may be important traits for rhizosphere competence and nodulation competitiveness. It should be noted, however, that our data cannot distinguish whether the acid sensitivity and loss of competitiveness displayed by the atvA mutants are causally related or are separate phenotypes of a pleiotropic mutation.

The Tn5 insertion in strain 899-PV4 disrupted a gene with strong sequence similarity to the A. tumefaciens chromosomal virulence gene $a c v B$ (Wirawan et al. 1993). Even though several reports exist on this gene and its paralog virJ (Fujiwara et al. 1998; Kalogeraki and Winans 1995; Kang et al. 1994; Majumder et al. 1999; Pan et al. 1995), a biochemical function for AcvB or VirJ has not been previously described. Our protein domain analyses suggest that AcvB-like proteins may represent a new family of lipolytic enzymes (Arpigny and Jaeger 1999; Jaeger et al. 1999), as they all contain the LIPASE_SER (PS00120) motif and conserved D and $\mathrm{H}$ residues that may conform the catalytic triad of this type of enzymes (Brady et al. 1990). The Ser-Ala replacement experiment in the AtvA lipase motif demonstrated that the $\mathrm{S}$ residue is critical for the protein's function, as expected for enzymes with a lipase, esterase, or acyl transferase activity (Brady et al. 1990; Brumlik and Buckley 1996; Jaeger et al. 1999). However, using AtvA as

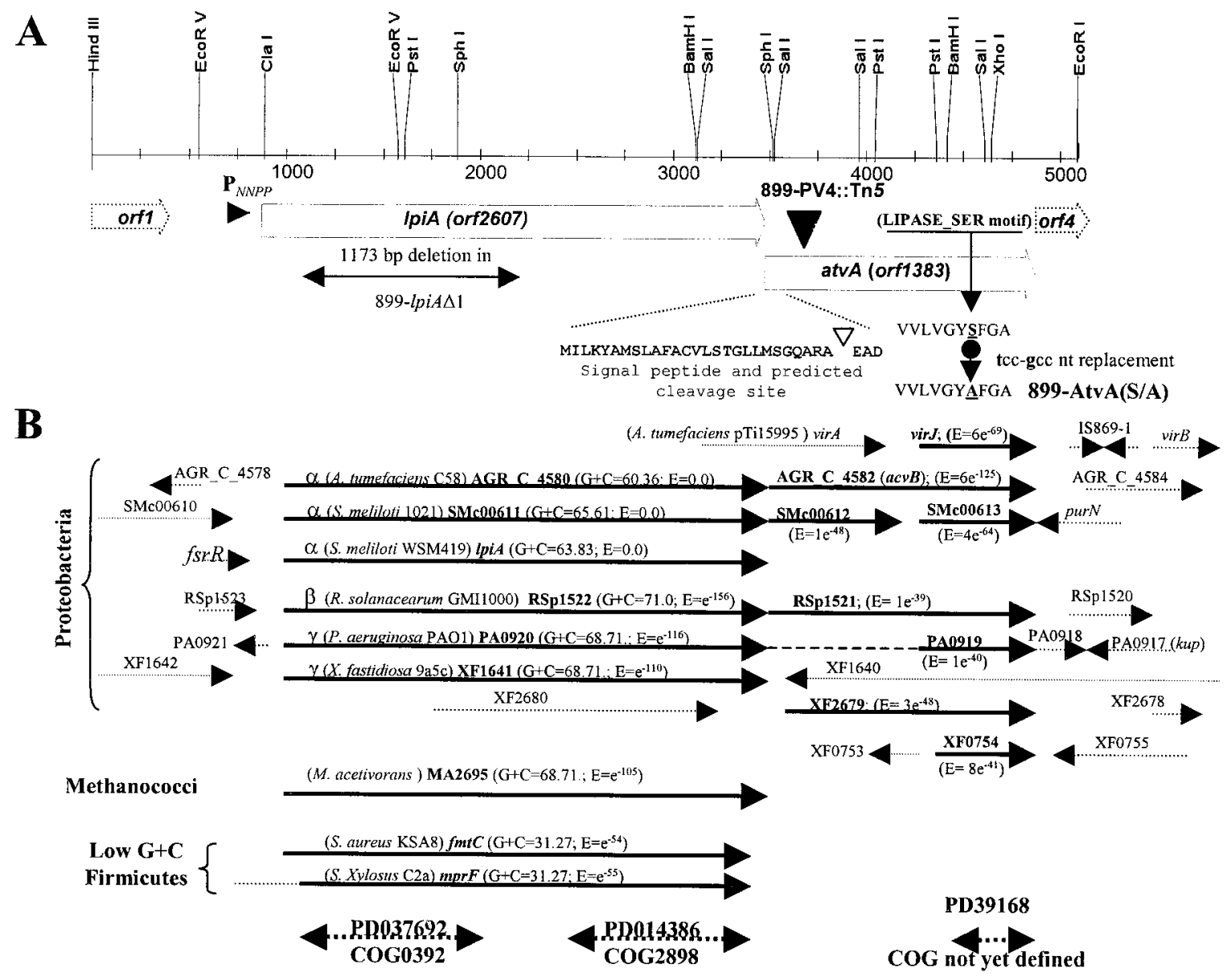

C
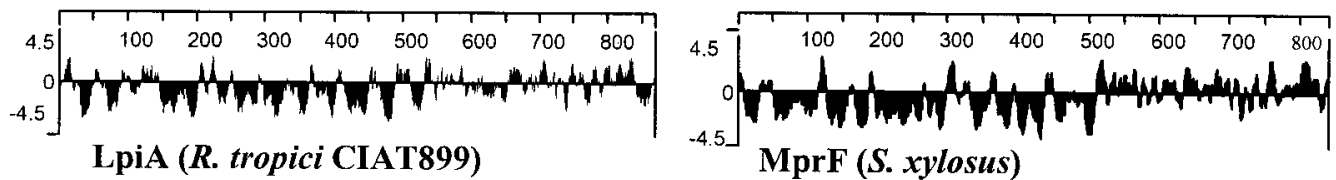

Fig. 2. A, Genetic and physical maps of the 5,077-bp insert of pPV4EH-MCS3 used for complementation studies. Shown are a restriction map, the location of a potential promoter $\left(\mathrm{P}_{\mathrm{NNPP}}\right)$, as predicted by the neural network for promoter predictions, the location of the DNA stretch deleted in strain 899lpiAA1, the Tn5 insertion site in strain 899-PV4, and the locations and sequences of the signal peptide and LIPASE_SER motif of AtvA, as well as that of its mutagenized version in strain 899-AtvA(S/A). B, Schematic multiple alignment of representative BLASTP subject hits (solid bar arrows) to ORF2607 and AtvA queries in the proteobacterial lpiA and $a c v B$ gene families, respectively, as well as ORF2607 subject hits with members of the FmtC/MprF family of integral membrane proteins from low G+C Firmicutes. The G+C values of ORF2607 subject hits, and E values for ORF2607 and AtvA hits are indicated. Dotted arrows represent the neighboring genes to each subject sequence, when known. Dashed lines indicate introduced alignment gaps. Dotted double arrow heads indicate the localization of particular ProDom domains and COG entries on the aligned sequences. Further members of the LpiA family were found at the general and microbial genomes databases in several genera of the $\alpha, \beta$, and $\gamma$ Proteobacteria and Methanococci in the genus Methanosarcina. Other members of the acvB/virJ family were found in several genera of the $\alpha, \beta$, and $\gamma$ Proteobacteria. C, Kyte-Doolittle hydrophilicity plot of LpiA from $R$. tropici CIAT899 compared with that of MprF from the low $\mathrm{G}+\mathrm{C}$ gram positive Staphylococcus xylosus, the latter being involved in resistance to cationic antimicrobial peptides. 
query in BLASTP and PSI-BLAST searches retrieved only a few weak matches to lipolytic enzymes; those with the highest scores being the putative lipase CPE1581 of Clostridium perfringens and the esterase/lipase 1 from Mycoplasma pulmonis (CAC13211). This is not surprising, since the members of the eight families of lipolytic enzymes currently recognized display only a very limited sequence similarity between them (Arpigny and Jaeger 1999). However, we should underscore that, at the present time, we do not have biochemical data to demonstrate that AtvA has a lipolytic activity. Furthermore, with the available data, we cannot elaborate a model explaining the acid sensitivity of strains 899-PV4 and 899-AtvA(S/A). Noteworthy, we discovered that the A. tumefaciens acvB strain B119 is also acid sensitive, a phenotype not previously reported for this strain. Since a low $\mathrm{pH}$ is required for the transcriptional activation of vir operons in agrobacteria by the VirA/VirG two-component regulatory system (Zhu et al. 2000), acid tolerance or habituation may be an important trait for agrobacterial virulence. Since the agrobacterial $a c v B$ locus is not induced by acetosyringone (Kalogeraki and Winans 1995), it will be interesting to test whether it is upregulated in response to $\mathrm{pH}$ downshift, as in CIAT899.

The experiments with the complemented strains 899PV4(pKW 1), 899-PV4(pPV4EH-MCS3), B119(pKW and B119(pPV4EH-MCS3) demonstrated that $a c v B$ and its rhizobial counterpart atvA are orthologs and that this gene is required both for acid tolerance and virulence in $A$. tumefaciens. Importantly, plasmids pKW $\Delta 1$ and pPV4EH-MCS3 were not able to complement the symbiotic phenotype of 899PV4, evidencing a polar effect of the Tn5 insertion. This interpretation is reinforced by the phenotypes (acid sensitive, $\mathrm{Fix}^{+}$) of strain 899-AtvA(S/A). Since the symbiotic proficiency and acid tolerance of strain 899-PV4 could be restored with pPV4cos 1 in trans, we conclude that its phenotypes are solely due to the insertion in atvA and not due to one or more secondary mutations. Very few rhizobial mutants have been described that are blocked at the stage of host cell invasion and bacteroid differentiation before the onset of $\mathrm{N}_{2}$ fixation (Oke and Long 1999b). Strain CIAT899-PV4 is blocked at this intermediate stage of nodule ontogeny (Cermola et al. 2000). These observations explain the $\mathrm{Fix}^{-}$and $\mathrm{Ndv}^{-}$phenotypes of the nodules induced by 899-PV4 (data not shown).

Based on the gene arrangement at the locus (Fig. 2A), the complementation experiments also demonstrated the existence of a promoter that maps to the intergenic region located upstream of lpiA, which is consistent with the prediction made by the neural network for promoter predictions (Reese et al. 1996). RNA dot blot hybridization experiments demonstrated that the promoter of this operon is acid responsive, as previously reported for the S. meliloti WSM419 lpiA locus (Glenn et al. 1999).

With the exception of SMc00613, virJ, XF0754, and $\mathrm{XF} 2679$, the other $a c v B$-like genes are preceded by an ORF strongly resembling lpiA (Fig. 2B). LpiA orthologs confirm a novel proteobacterial family of integral membrane proteins that display 13 transmembrane helices, which is structurally and phylogenetically related to the membrane proteins $\mathrm{MprF}$ and FmtC from low $\mathrm{G}+\mathrm{C}$ gram positives (Figs. 2B and 2C). Recently, the Staphylococcus aureus and Staphylococcus xylosus MprF proteins were shown to represent a novel virulence factor involved in the bacterial escape from innate host defenses. $\mathrm{MprF}$ is involved at an unknown step in the synthesis of lysylphosphatidylglycerol, which, due to its positive net charge, leads to repulsion of cationic, membrane-damaging peptides such as defensins, protegrins, and other host defense peptides (Peschel et al. 2001). Since defensin-like peptides also play a key role in plant defense against microbial infections (GarcíaOlmedo et al. 1998; Zasloff 2002), this may explain the presence of MprF-related genes in plant-associated microbes. The sevenfold reduction in competitiveness exhibited by the nonpolar deletion mutant 899-lpiA $\Delta 1$ highlights the requirement of IpiA for an optimal performance of CIAT899 in symbiosis with $P$. vulgaris. It remains to be shown if this loss of competitiveness is due to an increased sensitivity of the mutant to plant defense peptides. The $S$. meliloti mutant strain WR101, which carries a mTn5-GNm insertion in the lpiA locus of WSM419, was reported to lack a symbiotic phenotype (Glenn et al. 1999), since it forms $\mathrm{N}_{2}$-fixing nodules on its host. However, competition experiments were not performed with strain Wr101. Noteworthy, the use of a suitable gusA-tagged reporter strain such as 899-G1 for quantitative competition studies (Streit et al. 1992; Wilson et al. 1995) allowed us to uncover quantitative genetic effects of the mutations carried by strains 899-lpiA41, 899-AtvA(S/A), and 899-PV4, which have increasing detrimental effects on competitive $P$. vulgaris nodulation (Table 2).

Our future work will focus on the characterization of the symbiotically relevant genes located in the operon downstream of $\operatorname{atv} A$, the elucidation of the biochemical function of LpiA and AcvB-like proteins, and the reconstruction of their evolutionary history.

\section{MATERIALS AND METHODS}

\section{Bacterial strains and plasmids.}

The bacterial strains and plasmids used in this work are listed in Table 3. Rhizobium tropici CIAT899 was routinely grown in 20E (Werner et al. 1975) or yeast mannitol agar

Table 2. Results of Phaseolus vulgaris nodule occupancy competition experiments ${ }^{\mathrm{a}}$

\begin{tabular}{|c|c|c|c|c|}
\hline \multirow[b]{2}{*}{ Competing strains } & \multicolumn{2}{|r|}{ LN, pH 6.8} & \multicolumn{2}{|r|}{ LN, pH 5.8} \\
\hline & Ratio $^{\mathbf{b}}$ & $\%$ nodule occupancy \pm standard error ${ }^{c}$ & Ratio $^{\mathbf{b}}$ & $\%$ nodule occupancy \pm standard error ${ }^{c}$ \\
\hline 899-G1:CIAT899 & $1: 1$ & $47 \pm 4(n=12)$ & $1: 1$ & $53 \pm 4(n=9)$ \\
\hline 899-G1:CIAT899 & $1: 10$ & $11 \pm 1(n=12)$ & $1: 10$ & $12 \pm 2(n=9)$ \\
\hline 899-G1:CIAT899 & $10: 1$ & $87 \pm 6(n=12)$ & $10: 1$ & $91 \pm 7(n=9)$ \\
\hline 899-G1:899-PV4 & $1: 1$ & $100 \pm 0(n=4)$ & $1: 1$ & $100 \pm 0(n=4)$ \\
\hline 899-G1:899-PV4 & $1: 100$ & $98.5 \pm 3(n=4)$ & $1: 100$ & $97.3 \pm 3(n=4)$ \\
\hline 899-G1:899-AtvA (S/A) & $1: 1$ & $99.2 \pm 3(n=6)$ & ND & ND \\
\hline 899-G1:899-AtvA (S/A) & $1: 10$ & $90.7 \pm 1(n=6)$ & ND & ND \\
\hline 899-G1:899-lpiA $\Delta 1$ & $1: 1$ & $92.7 \pm 2(n=6)$ & ND & ND \\
\hline 899-G1:899-lpiA $\Delta 1$ & $1: 10$ & $57 \pm 3(n=6)$ & ND & ND \\
\hline
\end{tabular}

a The experiments were carried out between gusA-tagged reporter strain 899-G1, wild-type CIAT899, and mutants 899-PV4, 899-AtvA(S/A), and 899-lpiA $\triangle 1$ in Leonard jars with LN (N-free nutrient solution) buffered with $10 \mathrm{mM}$ MES at the indicated pH values. Plants were harvested $21 \mathrm{dpi}$.

$\mathrm{b}$ The inoculum ratios were adjusted based on optical density measurements of logarithmically growing cultures $\left(\mathrm{OD}_{600} \sim 0.5\right)$.

${ }^{c}$ Percentage of nodules occupied by the reporter strain 899-G1 after appliying a correction factor derived from viable cell counts of applied inocula. Nodule numbers per plant ranged from 57 to 247 . Double nodule occupancies typically occurred at a frequency of 1 to $4 \%$ and are not shown. ND $=$ not determined. 
(YMA) medium (Somasegaran and Hoben 1994) at $28^{\circ} \mathrm{C}$. Escherichia coli strains were grown in Luria-Bertani medium (Sambrook et al. 1989) at $37^{\circ} \mathrm{C}$.

\section{Tn5 mutagenesis of Rhizobium tropici CIAT899 and the isolation of acid-sensitive mutants.}

A general Tn5 mutagenesis of Rhizobium tropici CIAT899 was performed via conjugal transfer of pSUP1021 into CIAT899 using E. coli S17-1 as the donor strain (Simon et al. 1983). Appropriate dilutions of the conjugation mixture were plated on 20 E plates ( $\mathrm{pH}$ 6.8) amended with $150 \mu \mathrm{g}$ of kanamycin per ml (Km 150) and $150 \mu \mathrm{g}$ of streptomycin per ml (Sm 150) to select for Tn5-tagged transconjugants. Purified colonies were transferred individually into microtiter plate wells and were grown overnight at $28^{\circ} \mathrm{C}$. Selection of acid-sensitive mutants was performed by replica-plating of the ordered mutant bank onto YMA, $20 \mathrm{E}$, and the minimal medium described by Kingsley and Bohlool (1992), adjusted to pH 6.8 (MM, buffered with $20 \mathrm{mM}$ 2-[N-Morpholino]ethanesulfonic acid [MES]; Research Organics, Cleveland, OH, U.S.A.), pH 4.2, or 4.5 (MAM, buffered with $25 \mathrm{mM}$ Homopiperazine-N,N'-bis-2[ethanesulfonic] acid [Homopipes]; Research Organics), and amended with appropriate antibiotics. The MM and MAM were solidified with $0.8 \%$ gelrite (Carl Roth GmbH, Karlsruhe, Germany).

\section{Conjugal transfer}

of a $R$. tropici CIAT899 cosmid library into CIAT899-PV4.

A cosmid library of $R$. tropici CIAT899 made in pVK101 using partially digested HindIII genomic DNA fragments (Vargas et al. 1990) was mobilized en masse into CIAT899-PV4 by triparental matings using pRK2013 as the helper plasmid (Figurski and Helinski 1979). Transconjugants were selected on MAM plates (pH 4.2) amended with $\mathrm{Km} \mathrm{100,} \mathrm{Sm} \mathrm{75,} \mathrm{and} 7.5 \mu \mathrm{g}$ of tetracycline $(\mathrm{Tc})$ per $\mathrm{ml}$.

\section{Plant cultivation and inoculation with rhizobia.}

For nodulation assays, bean seeds (Phaseolus vulgaris L. cv. Saxa; Cornhaus Cölbe, Germany) were surface-sterilized, germinated, and inoculated with approximately $10^{3} \mathrm{CFU}$ per seedling, as previously described (Vinuesa et al. 1999). Inoculated seedlings were transplanted either into growth-pouches or Leonard jars, using $\mathrm{N}$-free leguminous (LN) nutrient solution (Werner et al. 1975). Plants were grown in a controlled growth chamber as described previously (Vinuesa et al. 1999).

\section{Construction of a gusA-tagged CIAT899 reporter strain} and its use in nodule occupancy competition experiments.

Competition experiments for nodule occupancy were performed either in growth pouches or in Leonard jars with buffered (10 mM MES) LN adjusted to $\mathrm{pH} 6.8$ or 5.5, using a low inoculum dose (around $10^{3} \mathrm{CFU}$ per plant). A gusA-tagged derivative of strain CIAT899 was obtained after mutagenesis with mTn5gusA30 (Wilson et al. 1995), a minitransposon that expresses the gusA gene under control of the nifH promoter. GUSstaining of nodulated root systems was performed with $100 \mu \mathrm{g}$ of $\mathrm{X}$-Gluc per 1 (Carl Roth) in phosphate buffer (pH 7.0), as described (Wilson et al. 1995). The experiments were repeated three times with four replicates per treatment.

\section{Agrobacterium tumefaciens virulence tests.}

Virulence tests were performed either on Kalanchöe pinnata leaves or on Nicotiana tabacum cv. petite Havanna leaf stripes, following standard procedures (Matsumoto et al. 1986).

\section{Standard DNA manipulations.}

Plasmid DNA was isolated from E. coli cultures using either the wizard mini- or midi-preps kit (Promega, Mannheim,
Germany). Restriction and DNA modifying enzymes were purchased from U.S. Biochemicals (USB-Amersham International, Little Chalfont, U.K.) and used following the instructions of the manufacturer and standard procedures (Sambrook et al. 1989). Genomic DNA from $R$. tropici was isolated following a cetyltrimethylammonium bromide-based protocol (Wilson 1990).

\section{PCR amplifications and generation of DIG-labeled hybridization probes.}

All PCR amplifications were carried out in a Perkin Elmer 2400 thermocycler using either 1.25 U Taq (USB-Amersham International) or $2 \mathrm{U} P f u$ polymerase (Promega), and the standard $50 \mu \mathrm{l}$ PCR mix described previously (Vinuesa et al. 1999). DIG-labeled PCR probes for Southern hybridization were generated by the incorporation of DIG-UTP (Roche Molecular Biochemicals, Mannheim, Germany) into amplification products, as previously described (Vinuesa et al. 1999). Primers for the amplification of a fragment of the Tn5 nptII marker were previously reported (Pillai et al. 1992). To amplify the Tn5 insertion junction cloned in p899PV4BSK, primer combinations M13 universal (reading into the multiple cloning site of pSK) and Tn5-77/58EB cagaattcggatcctaggaggtcacatggaagtc $\left(5^{\prime}\right.$ to $3^{\prime}$ notation) were used with $55^{\circ} \mathrm{C}$ annealing temperature and 2 min of extension time at $72^{\circ} \mathrm{C}$. The latter reads outwardly from the Tn5 IS50 elements, binding at positions 77 to 58 of the sequence with accession number U15572, having additional EcoRI and BamHI sites at its $5^{\prime}$ end for cloning purposes (underlined). All PCR-primers were synthesized by MWG Biotech (Ebersberg, Germany).

\section{DNA sequencing and sequence analyses.}

Overlapping subclones of pPV4EH-SK were made in pBluescript SK, and both strands of the resulting plasmids were subjected to cycle-sequencing in a T-gradient thermocycler (Biometra, Göttingen, Germany), using IRD-labeled M13f/M13r primers (MWG-Biotech) and the Thermosequenase fluorescent labeled primer cycle sequencing kit with 7deaza-dGTP (USB-Amersham International) and a model 4000 Li-COR automatic DNA sequencer, as previously described (Vinuesa et al. 1999).

Standard sequence editing and analysis was performed with the DNASTAR software package (Lasergene, Madison, WI, U.S.A.). The search for coding regions was performed with FrameD and the coding probability of ORFs was calculated with the Codon Frequency Analyzer software from Ballyclaire Analysis. Remote searches for sequence and domain similarities were performed at the NCBI server using the different BLAST programs at the general and microbial genomes data-

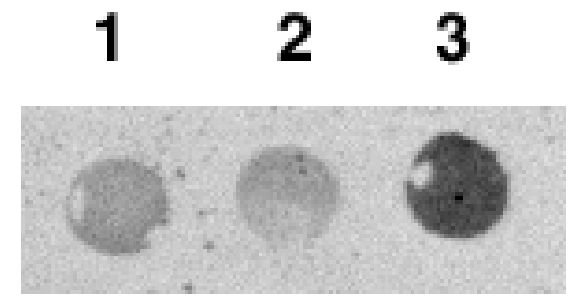

Fig. 3. Analysis of the transcriptional output of the atvA operon in Rhizobium tropici CIAT899. RNA dot blots were hybridized with a runoff digoxigenin-labeled transcript derived from p899PV4E-PCR under stringent conditions. RNA was isolated from CIAT899 cultures grown at $\mathrm{pH} 6.8$ (dot 1), 5.5 (dot 2), or after $1 \mathrm{~h}$ acid shock ( $\mathrm{pH} 6.8$ down to 4.7 ; dot 3 ). Quantitative analysis of the hybridization signals indicated that the atvA locus is constitutively transcribed at neutral and mild acid growth conditions, its expression being 3.8-fold upregulated $( \pm 0.23 ; n=$ 3) after acid shock. 
bases and the COG database. Searches for protein sequence motifs, domains, and predictions of their cellular locations were performed at the Prosite, ProDom, PSORT, and TMpred program servers.

\section{Construction of a nonpolar CIAT899 lpiA deletion mutant.}

Primer pairs PV4-662f-E (aaagaattcagccgggtgaatgacaaaatcc) and PV4-1129r-B (aaaggatccagggcggcgaaactcag) and PV42302f-B (tttggatccatcggcgccatcgtcgtg) and PV4-2778r-H (tttaagcttcatcggcgcaataggagag) were used to amplify with $P f u$ DNA polymerase two fragments internal to orf2607, corresponding to the hydrophobic domain of lpiA (the positions at which the primers bind on the sequence AF433669 are indicated in the primer designations, and restriction sites are underlined). These PCR fragments were digested with Eco RI+BamHI and BamHI+HindIII, respectively, and directionally cloned into pK18mobsacB (Schäfer et al. 1994) linearized with EcoRI and HindIII. The resulting plasmid p899lpiA $\Delta 1 \mathrm{~ms}$ was conjugally transferred into CIAT899. Single recombinants were selected on MM plates supplemented with $100 \mu \mathrm{g}$ of kanamycin per $\mathrm{ml}$. These were purified by repeated streaking on selective MM plates, after which single clones were grown to the end of exponential phase in $20 \mathrm{E}$ batch cultures, and serial dilutions were plated on $20 \mathrm{E}$ plates amended with $11 \%$ saccharose to select for double recombinants. Candidate clones were checked for the loss of the kanamycin resistance marker linked to the plasmid. Southern hybridization and PCR analysis with primers PV4-662f-E and PV4-2778r-H was used to verify the 1,173-bp-long deletion in strain 899-lpiA $\Delta 1$.

\section{Site-directed mutagenesis.}

A 1.2-kb DNA fragment centered around the LIPASE_SER motif of AtvA was amplified using primers PV4-3840f (aagaattcagcacctatcaattgc) and PV4-5057 (aaagcttggcgaacctttctggata) with $P f u$ polymerase (Stratagene, La Jolla, CA, U.S.A.) This fragment was cloned into the EcoRI and HindIII sites of the mobilizeable and integrative vector $\mathrm{pK} 18$ mobsacB (Schäfer et al. 1994), resulting in pPVatvA-18ms. This plasmid was used as the template for site-directed mutagenesis using the QuickChange mutagenesis system (Stratagene) with the complementary mutagenizing primers 899atvA_mut(S/A)F (gctggttggttatgcctttggcgccg) and 899atvA_mut(S/A)R (cggcgccaaaggcataaccaaccagc), following the instructions of the manufacturer. These were designed to introduce a tcc-gcc point mutation resulting in a Ser-Ala replacement. The resulting mutagenizing plasmid was designated pAtvA(S/A)-18ms and was confirmed by sequence analysis to contain the indicated $\mathrm{t} / \mathrm{g}$ replacement. This plasmid was used to mutagenize

Table 3. Bacterial strains and plasmids

\begin{tabular}{|c|c|c|}
\hline Strain or plasmid & Relevant characteristics $^{\mathrm{a}}$ & Reference/source $^{\text {b }}$ \\
\hline \multicolumn{3}{|l|}{ Escherichia coli } \\
\hline DH5 $\alpha$ & recA1, $\Delta l a c U 169$, Ф80d lacZAM1 & Stratagene \\
\hline HB101 & supE44 hsdS20 ( $\left.\mathrm{r}_{-\mathrm{B}} \mathrm{m}_{-\mathrm{B}}\right)$ recA13 ara-14 proA2 lacY1 galK2 rpsL20 syl-5 mtl-1 & New England Biolabs \\
\hline S17-1 & $\begin{array}{l}\text { thi pro } h s d R^{-} h s d M^{+} \text {recA, RP4 integrated in the chromosome, 2-Tc::Mu- } \\
\mathrm{Km}:: \operatorname{Tn} 7\left(\mathrm{Tp}^{\mathrm{r}} / \mathrm{Sm}^{\mathrm{r}}\right)\end{array}$ & Simon et al. 1983 \\
\hline \multicolumn{3}{|l|}{ Rhizobium tropici } \\
\hline CIAT899 ${ }^{\mathrm{T}}$ & (Phaseolus vulgaris/Colombia); acid tolerant, $\mathrm{Sm}^{\mathrm{r}}$ & Martínez-Romero et al. 1991/CIAT \\
\hline CIAT899-G1 & $\begin{array}{l}\text { gusA-tagged CIAT } 899 \text { derivative carrying a single mTn } 5 \text { gusA } 30 \text { insertion, used as } \\
\text { reporter strain in competition experiments, } \mathrm{Sm}^{\mathrm{r}}, \mathrm{Sp}^{\mathrm{r}}\end{array}$ & This study \\
\hline 899-PV4 & $\begin{array}{l}\text { CIAT } 899 \text { derivative (atvA::Tn } 5) \text {, acid sensitive, symbiotically defective, } \mathrm{Sm}^{\mathrm{r}}, \mathrm{Km}^{\mathrm{r}} \text {, } \\
\text { acid sensitive and very poor competitor for bean nodule occupancy }\end{array}$ & This study \\
\hline 899-PV4(pPV4EH-MCS3) & 899-PV4 carrying pPV4EH-MCS3 in trans, $\mathrm{Sm}^{\mathrm{r}}, \mathrm{Km}^{\mathrm{r}}, \mathrm{Tc}^{\mathrm{r}}$ & This study \\
\hline 899-lpiA $\triangle 1$ & $\begin{array}{l}\text { CIAT899 carrying a } 1173 \text { bp-long non-polar deletion in lpiA; } \mathrm{Sm}^{\mathrm{r}} \text {, poor competitor } \\
\text { for bean nodule occupancy }\end{array}$ & This study \\
\hline 899-AtvA(S/A) & $\begin{array}{l}\text { CIAT899 carrying a tcc/gcc point mutation (Ser/Ala replacement) in the AtvA } \\
\text { lipase motif; } \text { Sm}^{\text {r }} \text {, acid sensitive and very poor competitor for bean nodule } \\
\text { occupancy }\end{array}$ & This study \\
\hline \multicolumn{3}{|l|}{ Agrobacterium tumefaciens } \\
\hline B119 & Avirulent A208 (pTiT37, nopaline-type) derivative, $\operatorname{acv} B:: \mathrm{Tn} 5, \mathrm{Km}^{\mathrm{r}}$, acid sensitive & Wirawan et al. 1993 \\
\hline B119(pKW $\Delta 1)$ & B 119 carrying pKW $\Delta 1$ in trans, $\mathrm{Km}^{\mathrm{r}}$, Tc & Wirawan et al. 1993 \\
\hline B119(pPV4EH-MCS3) & B119 carrying pPV4EH-MCS3 in trans; virulent, $\mathrm{Km}^{\mathrm{r}}, \mathrm{Tc}^{\mathrm{r}}$ & This study \\
\hline \multicolumn{3}{|l|}{ Vector/plasmid } \\
\hline pBluescript II SK+ (pSK) & standard cloning and sequencing vector, $\mathrm{Ap}^{\mathrm{r}}$ & Stratagene, La Jolla, CA, U.S.A. \\
\hline pK18mobsacB & $\begin{array}{l}\text { Conjugative suicide vector with } \mathrm{Km}^{\mathrm{r}} \text { and } s a c B \text { markers used for positive selection } \\
\text { of double recombinants }\end{array}$ & Schäfer et al. 1994 \\
\hline pBBR1-MCS3 & Mobilizable broad host range cloning vector, $\mathrm{Tc}^{\mathrm{r}}$ & Kovach et al. 1995 \\
\hline pCAM130 & $\begin{array}{l}\text { Mobilizable suicide plasmid for mTn5gusA mutagenesis. Sm/Sp, Ap; } \\
\text { mTn5SSgusA30 (R. etli nifH-gusA-trpA ter translational fusion) in pUT/mini-Tn5 } \\
\text { Sm/Sp }\end{array}$ & Wilson et al. 1995 \\
\hline pSUP1011 & Mobilizable suicide plasmid for $\operatorname{Tn} 5$ mutagenesis & Simon et al. 1983 \\
\hline $\mathrm{pKW} \Delta 1$ & $\begin{array}{l}\text { pUCD2 derivative carrying the complete } a c v B \text { gene and upstream sequence and } \\
\text { restoring virulence in } \mathrm{B} 119, \mathrm{Tc}^{\mathrm{r}}\end{array}$ & Wirawan et al. 1993 \\
\hline pPV4cos1 & Cosmid complementing 899-PV4; 30-kb HindIII insert; $\mathrm{Tc}^{\mathrm{r}}$ & This study \\
\hline p899PV4BSK & 3.8-kb BamHI fragment from 899-PV4 carrying the Tn5 nptII marker; $\mathrm{Ap}^{\mathrm{r}}$ and $\mathrm{Km}^{\mathrm{r}}$ & This study \\
\hline P899PV4E-PCR & $\begin{array}{l}\text { 0.9-kb Pfu-amplified fragment from p899PV4BSK carrying flanking genomic DNA } \\
\text { of } 899-\mathrm{PV} 4 \text { and } 77 \mathrm{bp} \text { of the IS50L border cloned in the EcoRI site of } \mathrm{pSK} \text {; } \mathrm{Ap}^{\mathrm{r}}\end{array}$ & This study \\
\hline pPV4EH-SK & 5.1-kb EcoRI-HindIII subclone of pPV4cos1 in pSK; $\mathrm{Ap}^{\mathrm{r}}$ & This study \\
\hline pPV4EH-MCS3 & Insert of pPV4EH-SK subcloned as a KpnI-SmaI fragment in pBBR1-MCS3; $\mathrm{Tc}^{\mathrm{r}}$ & This study \\
\hline p899lpiA $11 m s$ & $\begin{array}{l}\text { Integrative mutagenizing plasmid based on pK18mobsacB used to construct strain } \\
\text { 899-lpiA } \triangle 1 ; \mathrm{Km}^{\mathrm{r}}\end{array}$ & This study \\
\hline $\mathrm{pAtvA}(\mathrm{S} / \mathrm{A})-18 m s$ & $\begin{array}{l}\text { Integrative mutagenizing plasmid based on pK18mobsacB used to construct strain } \\
\text { CIAT899-AtvA(S/A); } \mathrm{Km}^{\mathrm{r}}\end{array}$ & This study \\
\hline
\end{tabular}

\footnotetext{
${ }^{a}$ Host and origin of wild-type strain CIAT899.

${ }^{\mathrm{b}}$ CIAT is the Centro Internacional de Agricultura Tropical in Cali, Colombia.
} 
CIAT899 via marker exchange, using the positive $s a c B$ selection system for double recombinants on $20 \mathrm{E}$ plates amended with $11 \%$ saccharose (Schäfer et al. 1994).

\section{Analysis of the pH-dependent regulation of atvA by RNA dot blot hybridization.}

RNA was prepared from $10 \mathrm{ml}$ of exponentially growing batch cultures $\left(0.5<\mathrm{OD}_{600}<0.6\right)$ growing in buffered $20 \mathrm{E}$ medium (50 mM MES) at $\mathrm{pH}$ values of 6.8 and 5.5 , using the Ultrapure RNA isolation kit from Roche Molecular Biochemicals. Acid shock of a culture $\left(\mathrm{OD}_{600}=0.5\right)$ grown at $\mathrm{pH} 6.8$ was performed by sedimenting the cells by centrifugation and resuspending them in $10 \mathrm{ml}$ of $20 \mathrm{E}$ medium buffered $(50 \mathrm{mM}$ MES) at $\mathrm{pH} 4.7$ One microgram of RNA was transferred to Hybond Nylon membranes (Amersham Pharmacia Biotech, Freiburg, Germany) using a vacuum blotting apparatus (Machery-Nagel, Düren, Germany) and UV-cross-linked with a Stratalinker apparatus (Stratagene). A DIG-labeled runoff transcript of the cloned $R$. tropici atvA gene was synthesized using SacI-digested p899PV4E-PCR as template and a T3 RNA polymerase RNA-labeling kit (Roche Molecular Biochemicals) and was used as a hybridization probe PCR under stringent conditions $\left(68^{\circ} \mathrm{C}, 0.1 \% \mathrm{SSC}[1 \times \mathrm{SSC}\right.$ is $0.15 \mathrm{M} \mathrm{NaCl}$ plus $0.015 \mathrm{M}$ sodium citrate]) following the instructions of the manufacturer. Signal detection was performed with anti-DIG Fab fragments coupled to alkaline phosphatase (Roche Molecular Biochemicals) using the enhanced chemifluorescence substrate and a Storm 860 phosphorimager from Molecular Dynamics together with ImageQuant software (Amersham Pharmacia Biotech) for signal quantification.

\section{ACKNOWLEDGMENTS}

We thank M. Kojima for kindly providing us with strains B119 and B119/pKW 11 , J. Sanjuan and M. Megías for the gift of the CIAT899 cosmid library, A. Pühler for sending pK18mobsacB, H. Thierfelder for skillful technical assistance, S. Zauner for support with DNA sequencing, and M. Ullrich for providing the tobacco plants. Two anonymous reviewers are acknowledged for their constructive comments and suggestions, and O. Geiger is thanked for his critical reading of the manuscript. This work was supported by the German Science Foundation (DFG) through the SFB 395, by the European Union through the TMR-Network FMRXCT96-0039, and partially by DGAPA-UNAM from Mexico.

\section{LITERATURE CITED}

Aarons, S. R., and Graham, P. H. 1991. Response of Rhizobium leguminosarum bv. phaseoli to acidity. Plant and Soil 134:145-151.

Aranda-Rickert, A., Soria, M. A., and Correa, O. S. 2000. The adaptive acid response in Mesorhizobium sp. World J. Microbiol. Biotechnol. $16: 475-480$.

Arpigny, J. L., and Jaeger, K.-E. 1999. Bacterial lipolytic enzymes: Classification and properties. Biochem. J. 343:177-183.

Brady, L., Brzozowski, A. M., Derewenda, Z. S., Dodson, E., Doson, G., Tolley, S., Turkenburg, J. P., Christiansen, L., Huge-Jensen, B., Norskov, L., Thim, L., and Menge, U. 1990. A serine protease triad forms the catalytic centre of a triacylglycerol lipase. Nature 343:767770 .

Brumlik, M. J., and Buckley, J. T. 1996. Identification of the catalytic triad of the lipase/acyltransferase from Aeromonas hydrophila. J. Bacteriol. 178:2060-2064.

Cermola, M., Fedorova, E., Tate, R., Riccio, A., Favre, R., and Patriarca, E. J. 2000. Nodule invasion and symbiosome differentiation during Rhizobium etli-Phaseolus vulgaris symbiosis. Mol. Plant-Microbe Interact. 13:733-741.

Chen, H., Richardson, A. E., and Rolfe, B. G. 1993. Studies of the physiological and genetic basis of acid tolerance in Rhizobium leguminosarum biovar trifolii. Appl. Environ. Microbiol. 6:1798-1804.

Figurski, D. H., and Helinski, D. R. 1979. Replication of an origin-containing derivative of plasmid RK2 dependent on a plasmid function provided in trans. Proc. Natl. Acad. Sci. 76:1648-1652.

Foster, J. W. 1999. When protons attack: Microbial strategies of acid adaptation. Curr. Opin. Microbiol. 2:170-174.
Fujiwara, A., Takamura, H., Majumder, P., Yoshida, H., and Kojima, M. 1998. Functional analysis of the protein encoded by the chromosomal virulence gene $(a c v B)$ of Agrobacterium tumefaciens. Ann. Phytopathol. Soc. Jpn. 64:191-193.

Galibert, F., Finan, T. M., Long, S. R., Puhler, A., Abola, P., Ampe, F., Barloy-Hubler, F., Barnett, M. J., Becker, A., Boistard, P., Bothe, G., Boutry, M., Bowser, L., Buhrmester, J., Cadieu, E., Capela, D., Chain, P., Cowie, A., Davis, R. W., Dreano, S., Federspiel, N. A., Fisher, R. F., Gloux, S., Godrie, T., Goffeau, A., Golding, B., Gouzy, J., Gurjal, M., Hernandez-Lucas, I., Hong, A., Huizar, L., Hyman, R. W., Jones, T., Kahn, D., Kahn, M. L., Kalman, S., Keating, D. H., Kiss, E., Komp, C., Lelaure, V., Masuy, D., Palm, C., Peck, M. C., Pohl, T. M., Portetelle, D., Purnelle, B., Ramsperger, U., Surzycki, R., Thebault, P., Vandenbol, M., Vorholter, F. J., Weidner, S., Wells, D. H., Wong, K., Yeh, K. C., and Batut, J. 2001. The composite genome of the legume symbiont Sinorhizobium meliloti. Science 293:668-672.

García-Olmedo, F., Molina, A., Alamillo, J. M., and RodríguezPalenzuela, P. 1998. Plant defense peptides. Biopolymers 47:479-491.

Glenn, A. R., Reeve, W. G., Tiwari, R. P., and Dilworth, M. J. 1999. Acid tolerance in root nodule bacteria. Pages 112-130 in: Bacterial Responses to pH. R. I. Booth, ed. Wiley, Chichester, U.K.

Goss, T. J., O'Hara, G. W., Dilworth, M. J., and Glenn, A. R. 1990. Cloning, characterization, and complementation of lesions causing acid sensitivity in Tn5-induced mutants of Rhizobium meliloti WSM419. J. Bacteriol. 172:5173-5179.

Graham, P. H., Viteri, S. E., Mackie, F., Vargas, A. A. T., and Palacios, A. 1982. Variation in acid soil tolerance among strains of Rhizobium phaseoli. Field Crop Res. 5:121-128.

Graham, P. H., Draeger, K. J., Ferrey, M. L., Conroy, M. J., Hammer, B. E., Martínez, E., Aarons, S. R., and Quinto, C. 1994. Acid pH tolerance in strains of Rhizobium and Bradyrhizobium, and initial studies on the basis for acid tolerance of Rhizobium tropici UMR1899. Can. J. Microbiol. 40:189-207.

Howieson, J. G., and Ewing, M. A. 1986. Acid tolerance in the Rhizobium meliloti-Medicago symbiosis. Aust. J. Agric. Res. 37:153-155.

Jaeger, K.-E., Dijkstra, B. W., and Reetz, M. T. 1999. Bacterial biocatalysts: Molecular biology, three-dimensional structures, and biotechnological applications of lipases. Ann. Rev. Microbiol. 53:315-351.

Kalogeraki, V. S., and Winans, S. C. 1995. The octopine-type Ti plasmid pTiA6 of Agrobacterium tumefaciens contains a gene homologous to the chromosomal virulence gene $a c v B$. J. Bacteriol. 177:892-897.

Kang, H. W., Wirawan, I. G. P., and Kojima, M. 1994. Cellular localization and functional analysis of the protein encoded by chromosomal virulence gene $(a c v B)$ of Agrobacterium tumefaciens. Biosci. Biotech. Biochem. 58:2024-2032.

Kingsley, M. T., and Bohlool, B. B. 1992. Extracellular polysaccharide is not responsible for aluminum tolerance of Rhizobium leguminosarum bv. phaseoli CIAT899. Appl. Environ. Microbiol. 58:1095-1101.

Kovach, M. E., Elzer, P. H., Hill, D. S., Robertson, G. T., Farris, M. A., Roop, R. M. II, and Peterson, K. M. 1995. Four new derivatives of the broad-host-range cloning vector pBBR1MCS, carrying different antibiotic resistance cassettes. Gene 166:175-176.

LeVier, K., Phillips, R. W., Grippe, V. K., Roop, R. M. II, and Walker, G. C. 2000. Similar requirements of a plant symbiont and a mammalian pathogen for prolonged intracellular survival. Science 287:2492-2493.

Majumder, P., Takagi, K., Shioiri, H., Nozue, M., and Kojima, M. 1999. Functional analysis of two chromosomal virulence genes $c h v A$ and $a c v B$ of Agrobacterium tumefaciens using avirulent mutants with transposon 5 insertion in the respective gene. Ann. Phytopathol. Soc. Jpn. 65:254-263.

Marschner, H. 1995. Mineral Nutrition of Higher Plants. Academic Press, London.

Martínez-Romero, E., Segovia, L., Mercante, F. M., Franco, A. A., Graham, P., and Pardo, M. A. 1991. Rhizobium tropici, a novel species nodulating Phaseolus vulgaris L. beans and Leucaena sp. trees. Int. J. Syst. Bacteriol. 41:417-426.

Matsumoto, S., Machida, Y., and Tabeke, I. 1986. A rapid method for assaying tumorigenicity of Agrobacterium tumefaciens. Plant Mol. Biol. Rep. 4:42-47.

Mellor, R. B. 1989. Bacteroids in the Rhizobium-legume symbiosis inhabit a plant internal lytic compartment: Implications for other microbial endosymbioses. J. Exp. Bot. 40:831-839.

Nogales, J., Campos, R., BenAbdelkhalek, H., Olivares, J., Lluch, C., and Sanjuan, J. 2002. Rhizobium tropici genes involved in free-living salt tolerance are required for the establishment of efficient nitrogen-fixing symbiosis with Phaseolus vulgaris. Mol. Plant-Microbe Interact. 15:225-232.

O'Hara, G. W., and Glenn, A. R. 1994. The adaptive acid tolerance response in root nodule bacteria and Escherichia coli. Arch. Microbiol. $161: 286-292$ 
O’Hara, G. W., Goss, T. J., Dilworth, M. J., and Glenn, A. R. 1989. Maintenance of intracellular $\mathrm{pH}$ and acid tolerance in Rhizobium meliloti. Appl. Environ. Microbiol. 55:1870-1876.

Oke, V., and Long, S. R. 1999a. Bacterial genes induced within the nodule during the Rhizobium-legume symbiosis. Mol. Microbiol. 32:837849

Oke, V., and Long, S. R. 1999b. Bacteroid formation in the Rhizobiumlegume symbiosis. Curr. Opin. Microbiol. 2:641-646.

Pan, S. Q., Jin, S., Boulton, M. I., Hawes, M., Gordon, P. M., and Nester, E. W. 1995. An Agrobacterium virulence factor encoded by a Ti plasmid gene or a chromosomal gene is required for T-DNA transfer into plants. Mol. Microbiol. 17:59-269.

Parniske, M. 2000. Intracellular accommodation of microbes by plants: A common developmental program for symbiosis and disease? Curr. Opin. Plant Biol. 3:320-328.

Peick, B., Graumann, P., Schmid, R., Marahhiel, M., and Werner, D. 1999. Differential pH-induced proteins in Rhizobium tropici CIAT899 and Rhizobium etli CIAT611. Soil Biol. Biochem. 31:189-194.

Peschel, A., Jack, R. W., Otto, M., Collins, L. V., Staubitz, P., Nicholson, G., Kalbacher, H., Nieuwenhuizen, W. F., Jung, G., Tarkowski, A., van Kessel, K. P., and van Strijp, J. A. 2001. Staphylococcus aureus resistance to human defensins and evasion of neutrophil killing via the novel virulence factor $\mathrm{MprF}$ is based on modification of membrane lipids with 1-lysine. J. Exp. Med. 193:1067-1076.

Pillai, S. D., Josephson, K. L., Bailey, R. L., and Pepper, I. L. 1992. Specific detection of rhizobia in root nodules and soil using the polymerase chain reaction. Soil Biol. Biochem. 24:885-891.

Priefer, U. B., Aurag, J., Boesten, B., Bouhmouch, I., Defez, R., FilaliMaltouf, A., Miklis, M., Moawad, H., Mouhsine, B., Prell, J., Schluter, A., and Senatore, B. 2001. Characterisation of Phaseolus symbionts isolated from Mediterranean soils and analysis of genetic factors related to $\mathrm{pH}$ tolerance. J. Biotechnol. 91:223-236.

Pugsley, A. P. 1993. The complete general secretory pathway in gramnegative bacteria. Microbiol. Reviews 57:50-108.

Rainey, P. B. 1999. Adaptation of Pseudomonas fluorescens to the plant rhizosphere. Environ. Microbiol. 1:243-257.

Reese, M. G., Harris, N. L., and Eeckman, F. H. 1995. Large scale sequencing specific neural networks for promoter and splice site recognition. Pages 737-738 in: Biocomputing: Proceedings of the 1996 Pacific Symposium. L. Hunter and T. Klein, eds. World Scientific Publishing Co., Singapore.

Riccillo, P., Muglia, C., de Bruijn, F. J., Roe, A., Booth, I. R., and Aguilar, M. 2000. Glutathione is involved in environmental stress response in Rhizobium tropici, including acid tolerance. J. Bacteriol. 182:1748-1753.

Roth, L. E., Jeon, K. W., and Stacey, G. 1988. Homology in endosymbiotic systems: The term 'symbiosome.' Pages 220-225 in: Molecular Genetics of Plant-Microbe Interactions. R. Palacios and D. P. S. Verma, eds. American Phytopathological Society Press, St. Paul, MN, U.S.A.

Sambrook, J., Fritsch, E. F., and Maniatis, T. 1989. Molecular Cloning: A Laboratory Manual. Cold Spring Harbor Laboratory Press, Cold Spring Harbor, NY, U.S.A.

Schäfer, A., Tauch, A., Jäger, W., Kalinowski, G., Thierbach, G., and Pühler, A. 1994. Small mobilizable multi-purpose cloning vectors derived from the Escherichia coli plasmids pK18 and pK19: Selection of defined deletions in the chromosome of Corynebacterium glutamicum. Gene 145:69-73.

Simon, R., Priefer, U., and Pühler, A. 1983. A broad host range mobilization system for in vivo genetic engineering: Transposon mutagenesis in gram-negative bacteria. Bio/Technology 1:784-791.

Somasegaran, P., and Hoben, H. J. 1994. Handbook for rhizobia: Methods in legume-Rhizobium technology, Springer-Verlag, Heidelberg, Germany.

Steele, H., Vinuesa, P., Strümpeler, M., Schmid, R., and Werner, D. 2000. 2D SDS-PAGE analysis of proteins involved in acid tolerance in Rhizobium tropici CIAT899. Pages 481-482 in: Nitrogen Fixation: From Molecules to Crop Productivity. F. O. Pedrosa, M. Hungria, M. G. Yates, and W. E. Newton, eds. Kluwer Academic Publishers, Dordrecht, The Netherlands.

Streit, W., Kosch, K., and Werner, D. 1992. Nodulation competitiveness of Rhizobium leguminosarum bv. phaseoli and Rhizobium tropici strains measured by glucuronidase (gusA) gene fusion. Biol. Fertil.
Soils 14:140-144.

Tatusov, R. L., Natale, D. A., Garkavtsev, I. V., Tatusova, T. A., Shankavaram, U. T., Rao, B. S., Kiryutin, B., Galperin, M. Y., Fedorova, N. D., and Koonin, E. V. 2001. The COG database: New developments in phylogenetic classification of proteins from complete genomes. Nucleic Acids Res. 29:22-8.

Udvardi, M. K., and Day, D. A. 1997. Metabolite transport across symbiotic membranes of legume nodules. Annu. Rev. Plant Physiol. Plant Mol. Biol. 48:493-523.

Vargas, C., Martinez, J. L., Megias, M., and Quinto, C. 1990. Identification and cloning of nodulation genes and host specificity determinants of the broad host-range Rhizobium leguminosarum biovar phaseoli strain CIAT899. Mol. Microbiol. 11:1899-1910.

Vinuesa, P., Reuhs, B. L., Breton, C., and Werner, D. 1999. Identification of a plasmid-borne locus in Rhizobium etli KIM5s involved in lipopolysaccharide O-chain biosynthesis and nodulation of Phaseolus vulgaris. J. Bacteriol. 181:5606-5614.

Vlassak, K., Vanderleyden, J., and Franco, A. 1996. Competition and persistence of Rhizobium tropici and Rhizobium etli in tropical soil during successive bean (Phaseolus vulgaris L.) cultures. Biol. Fertil. Soils 21:61-68

Werner, D., Wilcockson, J., and Zimmermann, E. 1975. Adsorption and selection of rhizobia by ion exchange papers. Arch. Microbiol. 105:2732

Wilson, K. 1990. Preparation of genomic DNA from bacteria. Pages 241245 in: Current Protocols in Molecular Biology. F. M. Ausubel, R. Brent, R. E. Kingston, D. D. Moore, J. G. Seidman, J. A. Smith, and K. Struhl, eds. Greene Publishing Associates and John Wiley \& Sons, New York.

Wilson, K. J., Sessisch, A., C., C. J., Giller, K. E., Akkermans, A. D. L., and Jefferson, R. A. 1995. $\beta$-glucuronidase (GUS) transposons for ecological and genetic studies of rhizobia and other gram-negative bacteria. Microbiology. 141:1691-1705.

Wirawan, G. P., Kang, H. W., and Kojima, M. 1993. Isolation and characterization of a new chromosomal virulence gene of Agrobacterium tumefaciens. J. Bacteriol. 175:3208-3212.

Wood, D. W., Setubal, J. C., Kaul, R., Monks, D. E., Kitajima, J. P., Okura, V. K., Zhou, Y., Chen, L., Wood, G. E., Almeida, N. F., Jr., Woo, L., Chen, Y., Paulsen, I. T., Eisen, J. A., Karp, P. D., Bovee, D., Sr., Chapman, P., Clendenning, J., Deatherage, G., Gillet, W., Grant, C., Kutyavin, T., Levy, R., Li, M. J., McClelland, E., Palmieri, A., Raymond, C., Rouse, G., Saenphimmachak, C., Wu, Z., Romero, P., Gordon, D., Zhang, S., Yoo, H., Tao, Y., Biddle, P., Jung, M., Krespan, W., Perry, M., Gordon-Kamm, B., Liao, L., Kim, S., Hendrick, C., Zhao, Z. Y., Dolan, M., Chumley, F., Tingey, S. V., Tomb, J. F., Gordon, M. P., Olson, M. V., and Nester, E. W. 2001. The genome of the natural genetic engineer Agrobacterium tumefaciens C58. Science 294:2317-2323.

Zahran, H. H. 1999. Rhizobium-legume symbiosis and nitrogen fixation under severe conditions and in arid climate. Microbiol. Mol. Biol. Rev. 63:968-989.

Zasloff, M. 2002. Antimicrobial peptides of multicellular organisms. Nature 415:389-395.

Zhu, J., Oger, P. M., Schrammeijer, B., Hooykaas, P. J., Farrand, S. K., and Winans, S. C. 2000. The bases of crown gall tumorigenesis. J. Bacteriol. 182:3885-3895.

\section{AUTHOR-RECOMMENDED INTERNET RESOURCES}

DFrame webpage hosted by INRA: www.toulouse.inra.fr/FrameD.html

BLAST page hosted by NCBI: www3.ncbi.nlm.nih.gov/blast/

COG database page hosted by NCBI: www3.ncbi.nlm. nih. gov/ COG/xognitor.html

Prosite website hosted by North Carolina Supercomputing Center: www.expasy.ch/prosite/

The protein domain database ProDom: prodes.toulouse.inra.fr/prodom/ doc/prodom.htm

PSORT, the website for the program to predict protein localization sites in cells: psort.nibb.ac.jp/

TMPred server: www.ch.embnet.org/ software/TMPRED_form.html

NNPP, the website hosting the Neural Network for Promoter Predictions: www.fruitfly.org/seq tools/promoter.html 